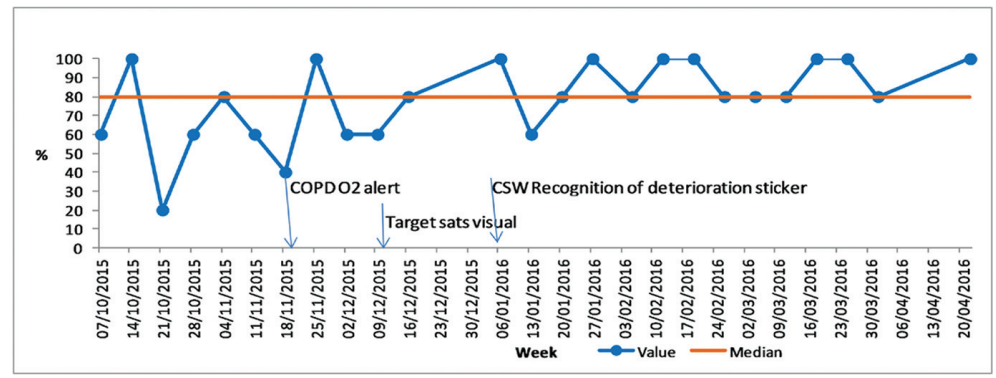

Abstract 920 Figure 5 Recognition of hypoxia

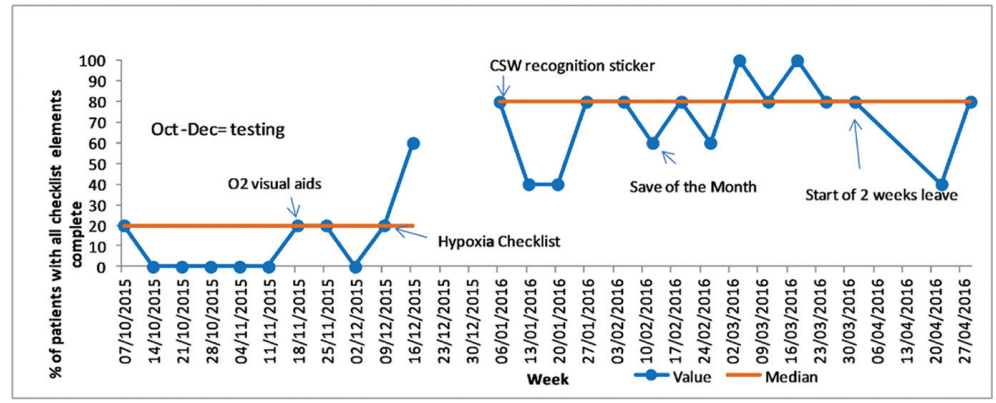

Abstract 920 Figure 6 Hypoxia response completion

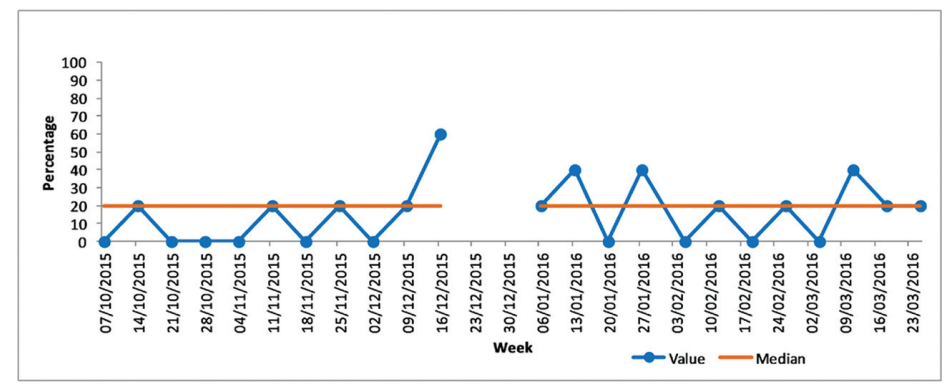

Abstract 920 Figure 7 Oxygen prescribed

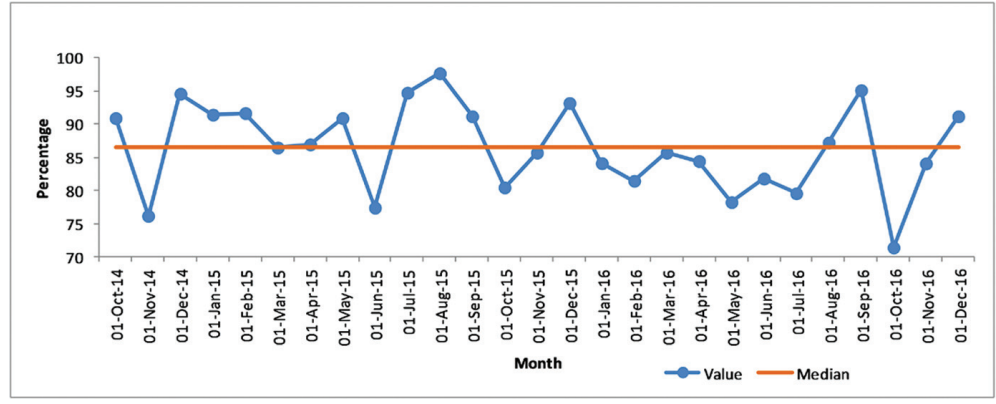

Abstract 920 Figure $8 \%$ of septic patients receiving IV antibiotics within one hour

\section{QUALITY IMPROVEMENT PRACTICE FACILITATION TO INCREASE DEPRESSION SCREENING AND BEHAVIOURAL HEALTH MANAGEMENT IN A PAEDIATRIC PRACTICE IN OHIO'S APPALACHIA}

Suzanne Hoholik, Christina Toth, Mike Fetzer, Rebecca Baum, Stephen Cardamone, Sean Gleeson. Nationwide Children's Hospital, US
Background Depression affects $12 \%$ to $20 \%$ of adolescents and up to $30 \%$ of Appalachian residents. Given its frequency, routine adolescent depression screening and management is recommended by the American Academy of Paediatrics. However, routine depression screening is limited. Quality improvement (QI) practice facilitators $(\mathrm{PF})$ can help clinicians standardise care, remove unwanted variation and improve outcomes. A QI PF model may improve depression screening and management. 


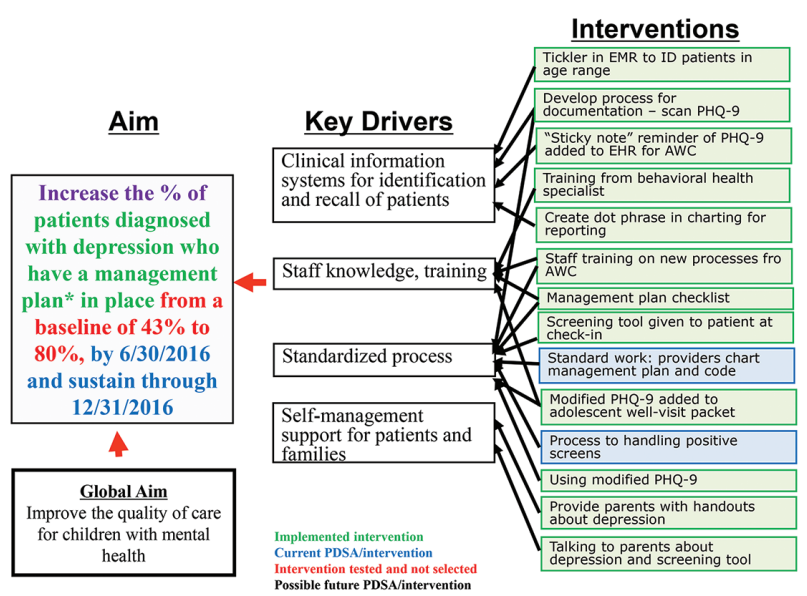

Abstract 927 Figure 1 Depression screening project
Objectives Increase use of a validated depression screening tool from $0 \%$ to $30 \%$, and create a management plan for those diagnosed with depression from $43 \%$ to $85 \%$ by $6 / 30$ / 2016 and sustain through 12/31/2016.

Methods QI PFs from Partners For Kids, an affiliate of Nationwide Children's Hospital, supported a practice in Ohio's Appalachia region to initiate a depression screening and management project with 6 months follow-up. PFs used the IHI Model for Improvement and led recurring, on-site meetings. Interventions included training from a $\mathrm{NCH}$ developmental and behavioural paediatrician, new workflows and implementing a change package - establishing referral sources, process to manage emergencies and effective management plan checklist. PFs performed regular audits of the project.

Results Screening for depression increased from 0\% to $42 \%$ within 3 months with initial QI interventions and increased to $80 \%$ with subsequent interventions. Documentation of evidence-based management of depression increased from $43 \%$ to

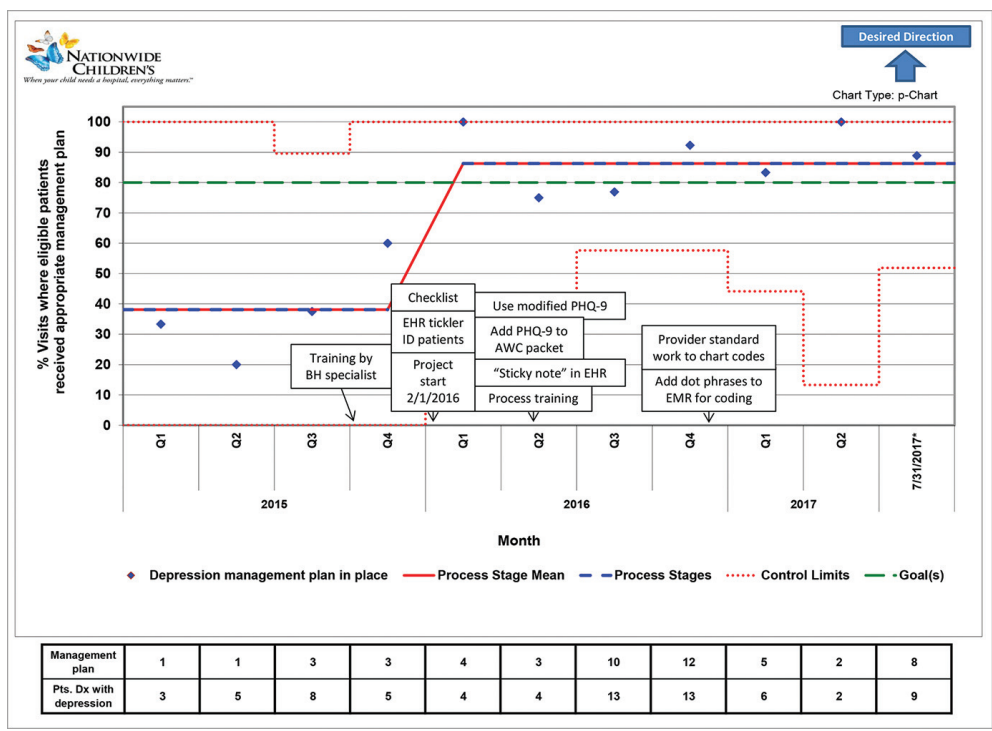

Abstract 927 Figure 2 Appropriate management plan for 11-18-year-olds identified with depression

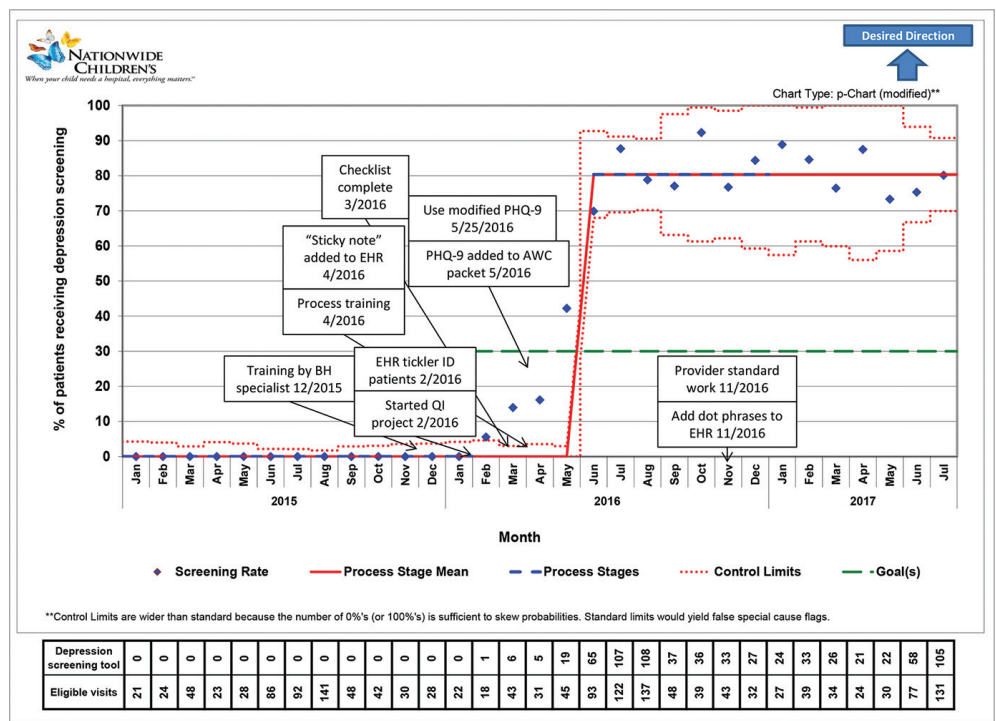

Abstract 927 Figure 3 Depression screening tool used during WCC of 11-18 year olds 
85\%. Depression diagnosis increased from 21 children in 2015 to 34 in 2016, a $62 \%$ increase.

Conclusions Implementing behavioural health recommendations using PF led to increased screening, diagnosis and management of depression at an Appalachian primary care practice.

\section{A QUALITY IMPROVEMENT INITIATIVE REDUCES CAST COMPLICATIONS IN A PAEDIATRIC HOSPITAL}

Julie Samora, Walter Samora, Kevin Dolan, Kevin Klingele. Nationwide Children's Hospital, US

\subsection{6/bmjoq-2017-|HI.15}

Background Casts are frequently used as routine treatment in paediatric orthopaedic practice, and yet are not without complications. At our large tertiary care paediatric hospital, baseline rate of all casting complications was 5.6 complications per 1000 casts applied $(0.56 \%)$.

Objectives The project aimed to decrease the overall cast complication rate and improve patient care using quality improvement (QI) methodology.

Methods We implemented quality improvement concepts derived from the Institute for Healthcare Improvement (IHI) models, including Plan-Do-Study-Act (PDSA) cycles, to perform a quality improvement initiative to decrease our cast complication rate. We developed a resident casting education program with a competency 'checklist' to ensure that casts are applied, bivalved, and removed in a safe and standardised manner to prevent patient harm. We implemented a policy and procedure change, requiring AquaCast Saw Stop Protective Strips to be applied with every cast application. We reviewed our facility's processes and procedures and determined adequate measures were in place to effectively manage inventory and maintenance of cast saw blades.

Results With the multi-modal QI intervention, our complication rate was reduced to 0.15 complications per one thousand applications, a more than $90 \%$ improvement.

Conclusions Implementation of QI concepts to perform a quality improvement initiative resulted in a shift toward fewer cast complications, leading to overall improved patient care at a large tertiary paediatric hospital.

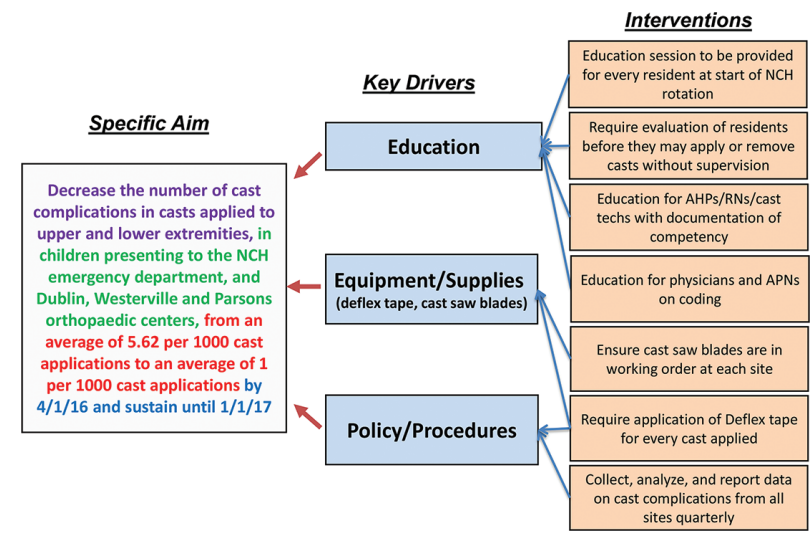

Abstract 935 Figure 1 Reduction of cast complications

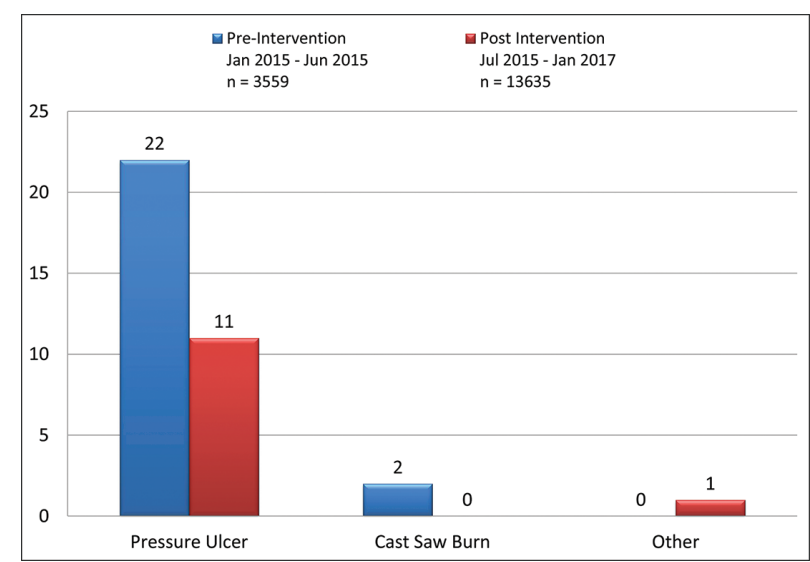

Abstract 935 Figure 3 Cast complications by category

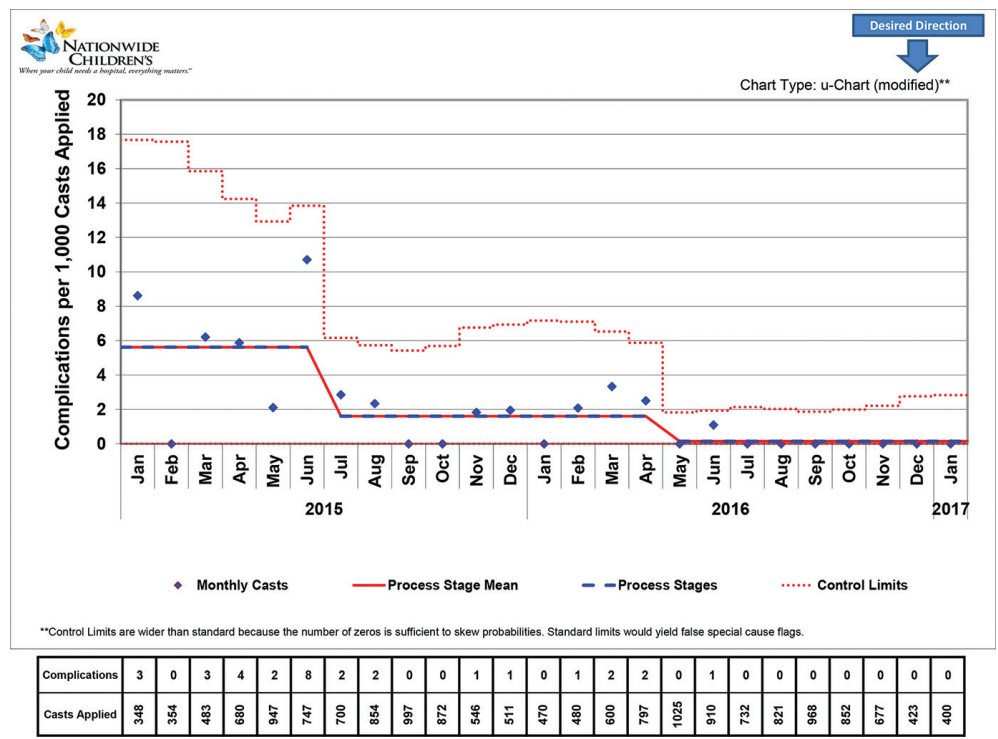

Abstract 935 Figure 2 Cast complications 